\title{
Discussion on Calculation Method of Social Stability Price of Farmland Requisition Price: Taking Bazhou City as an Example*
}

\author{
Yapeng Zhou ${ }^{1}$, Lin Liu ${ }^{2,3}$, Yang Yang $^{1}$, Li Zhang ${ }^{1}$, Hao Xu ${ }^{1}$, Yigong Zhang ${ }^{1, * *}$, \\ and Zhiwei $\mathrm{Li}^{1}$ \\ ${ }^{1}$ College of Natural Resources \& Environment Sciences, Agricultural University of Hebei, \\ Baoding 071001, China \\ ${ }^{2}$ School of Land Science and Technology, China University of Geosciences, Beijing 100083, \\ China \\ ${ }^{3}$ Shijiazhuang Engineering Technology School, Shijiazhuang 050061, China \\ \{zhouyp, zhangyg63\} @hebau. edu.cn
}

\begin{abstract}
Land is a kind of basic resources and of great importance to the survival and development of human beings. Due to the conflict between the limited amount of land and the unlimited development of human beings, land surely plays a significant role in national security and social development. The academic circle has introduced the social stability price to the pricing system of farmland, which reflects the social stability value of farmland. This paper analyses the composition of social stability function of farmland and takes Bazhou city as an example to discuss two calculation methods of social stability price of farmland, a direct method and an indirect method.
\end{abstract}

Keywords: Farmland, Social Stability Price, Calculation.

The farmland price we refer to at present usually only involves its productivity price, which is the price of farmland as productive power or a means of production, the opposite side of value in use. And the social value of farmland, which lies in the fact that farmland provides farmers with survival guarantee and social welfare, and farmland is also of the function of national security and social stability as it provides food for the society, is ignored. At present, knowledge of its social stability function and social stability price is just limited to the aspect of food security and the elaboration on its definition and functions is not clear and complete[1].

\section{Definition of the Social Stability Function and Price of Farmland}

The social stability function of farmland means the function that farmland performs so that the state and the social development can enjoy a safe and stable state which is

\footnotetext{
The paper is supported by the Hebei Provincial Department of education funding for a project, (project number is 2009451).

** Corresponding author.
}

D. Li and Y. Chen (Eds.): CCTA 2012, Part I, IFIP AICT 392, pp. 437443, 2013.

(C) IFIP International Federation for Information Processing 2013 
healthy, high-efficiency and not threatening and accepted by human beings. The risk of this kind of stable state is predictable and accepted by human beings.

The social stability price of farmland means that the social stability function of farmland is monetized or realized in the market, which becomes the social stability price of farmland.

Price is the embodiment of value and comes from the realization of function. In order to figure out the social stability price of farmland, the social stability function of farmland should be analyzed first, so that its social stability price can be obtained [2].

\section{The Composition, Characteristics and Influencing Factors of Social Stability Function of Farmland}

\subsection{The Composition of Social Stability Function of Farmland}

Generally speaking, the function of land lies in the four aspects, namely production function, environment function, bearing function and space function [3]. As far as farmland is concerned, its social stability function also lies in the four aspects. First, due to its productivity, farmland can yield various kinds of crops which are necessary for the survival of human being, meet the requirement of human beings for food, and ensure the food security. Second, farmland is a

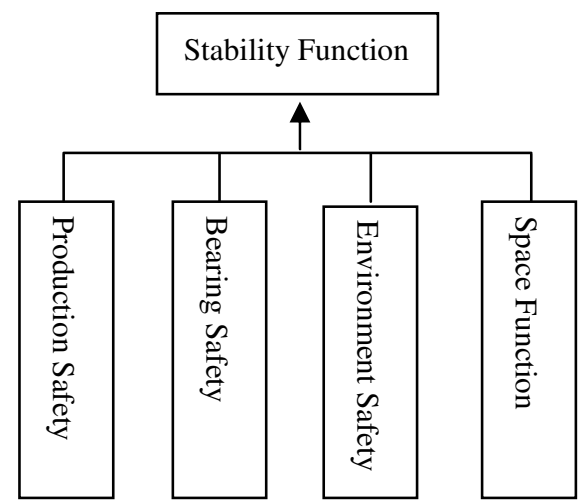

Fig. 1. Constitutional Diagram of Social Stability Function of Farmland constituent of the whole ecological environment and farmland is indispensable to ensure the structural integrity of the ecological environment and realization of its functions. Third, human beings carry out their activities on land and farmland as a constituent of land also serves the bearing function, which ensures the economic development and social stability and progress. Finally, as the survival and development of humans need some space and before they find a usable space in addition to the earth, land is the only choice of human beings (Figure 1).

\subsection{The Characteristics of Social Stability Function of Farmland}

Due to the characteristics of farmland and influence of the external environment on farmland, the social stability function of farmland is characterized by the following aspects: eternity, spatial differentiation, time variability, limited function, complicated influencing factors and various function ways. 


\subsection{The Influencing Factors of Social Stability Function of Farmland}

Farmland is an open complicated system, with many influencing factors of complicated functions. Our analysis reveals that the influencing factors that affect social stability function of farmland cover the following aspects (Table 1):

Table 1. Table of Influencing Factors of Social Stability Function of Farmland

\begin{tabular}{|c|c|c|}
\hline & $\begin{array}{c}\text { Aspects } \\
\text { Influenced }\end{array}$ & Influencing Factors \\
\hline \multirow{4}{*}{$\begin{array}{l}\text { Social } \\
\text { Stability } \\
\text { Function } \\
\quad \text { of } \\
\text { Farmland }\end{array}$} & Number & $\begin{array}{l}\text { taken up by construction, industrial restructuring of } \\
\text { agriculture, taken up by people and lying waste, destroyed } \\
\text { by natural disasters, etc. }\end{array}$ \\
\hline & Quality & $\begin{array}{l}\text { water resources, lighting, temperature, nutrients, } \\
\text { environment pollution, etc. }\end{array}$ \\
\hline & $\begin{array}{l}\text { Social } \\
\text { Economy }\end{array}$ & $\begin{array}{l}\text { safety quantity demanded within planning period, investment } \\
\text { in agriculture, local living standards, construction of } \\
\text { infrastructure, relevant policies, etc. }\end{array}$ \\
\hline & $\begin{array}{l}\text { Science and } \\
\text { Technology }\end{array}$ & $\begin{array}{l}\text { irrigation techniques and facilities, seed resources, } \\
\text { cultivation techniques, etc. }\end{array}$ \\
\hline
\end{tabular}

\section{Calculation of Price of Social Stability Function of Farmland}

The influence of various influencing factors on the function of farmland is reflected directly by price. There are two ways of price realization; one is direct calculation, which is rather difficult; the other one is indirect method, which evaluates the price in accordance with the substitution principle. The concrete ideas are as follows:

\subsection{Direct Calculation Method}

This calculation method begins with the social stability function of farmland, evaluates the importance of social stability function of farmland to the whole society, works out the weight of the function and then finds out the influencing factors that influence the security function of farmland. Taking the economic conditions and scientific levels into account, quantify these influencing factors and the social stability price of farmland is obtained. The calculation equation of social stability price in a unit area is as follows:

$$
\mathrm{S}=\mathrm{S} 1+\mathrm{S} 2+\mathrm{S} 3+\mathrm{S} 4
$$

In this equation, $S$ is the social stability price of farmland in a unit area.

$\mathrm{S} 1$ is the production safety price in a unit area.

$\mathrm{S} 2$ is the bearing safety price in a unit area.

$\mathrm{S} 3$ is the environment safety price in a unit area.

$\mathrm{S} 4$ is the space safety price in a unit area. 
The price of each function is the function of the influencing factors. The influencing factors are already listed in the table above and they can be used in calculation. The equation for the function price in a unit area of each part is

$$
\mathrm{SI}=f(\mathrm{X} 1, \mathrm{X} 2, \mathrm{X} 3, \ldots \mathrm{XI})
$$

In this equation, SI is the function price in a unit area of the four parts in the social stability function of farmland

$\mathrm{XI}$ is the various factors of stability function price in each part

The present conditions show that the influencing factors of the last three kinds of stability function price are of complicated function and it is hard to calculate the price. Therefore, production safety price is used to replace the stability price of the whole society temporarily.

\subsection{Indirect Calculation Method}

The calculation of the social stability price can be based on the substitution principle and use land reclamation fees as the quantized value of the social stability function, because the land reclamation fee is the compensation of value for land taken up. The charging of land reclamation fee is a economic means to ensure the dynamic balance of the total cultivated land in China and is the basis for food safety in the society. The determination of standards of land reclamation fees should first consider the land capital input of land with average quality levels, including tangible farmland water conservancy facilities and intangible soil economic fertility. For the tangible farmland water conservancy facilities, the quantity of value can be determined based on the replacement cost; for the intangible soil economic fertility, the formation cycle of soil fertility as well as the capital input each year within the cycle should be considered. According to the sum of capital input each year within the formation cycle of soil economic fertility, the quantity of value is determined by gains and losses of investment within the formation cycle of economic fertility. As far as soil fertility is concerned, due to difference in starting reclamation, hysteresis quality of reclamation benefit and gradualness of improving soil fertility, land reclamation fees are different. At present, for the wasteland which is easy to reclaim, it is predicted that in the first four years, there is profit, but not much. Generally, from the fifth year on, the profit begins to increase. Therefore, taking the input factors to form enough soil fertility and the losses of profit in the first four years, suppose the average input level of land reclamation is $\mathrm{T}$ yuan/mu, the yield level is $\mathrm{P}$ yuan/mu, the capitalization rate is $\mathrm{r}$, the average interest rate of recent years, so the present value of input for reclaiming wasteland for five years is

$$
\mathrm{V} 1=\mathrm{T}+\mathrm{T} /(1+\mathrm{r})+\mathrm{T} /(1+\mathrm{r}) 2+\mathrm{T} /(1+\mathrm{r}) 3+\mathrm{T} /(1+\mathrm{r}) 4
$$

The present value of loss in revenue in four years is

$$
\mathrm{V} 2=\mathrm{P} /(1+\mathrm{r})+\mathrm{P} /(1+\mathrm{r}) 2+\mathrm{P} /(1+\mathrm{r}) 3+\mathrm{P} /(1+\mathrm{r}) 4
$$

The social stability price of farmland $\mathrm{V}=\mathrm{V} 1+\mathrm{V} 2$. With the land development and management gathering momentum and increase of demand for land from the society, 
land reserve resources are decreasing day by day, land reclamation becomes more and more difficult and the land reclamation fees will increase day by day.

\section{An Attempt to Calculate the Social Price of Farmland in Bazhou City}

\subsection{A Brief Introduction to Bazhou City}

Bazhou city is located in the south-central part of Hebei province and the center of the triangle area formed by Beijing, Tianjin and Baoding. With the north latitude of

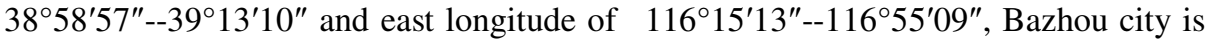
situated at the semiarid continental monsoon climate zone in temperate zone. Adjacent to Tianjin and Wuqing on the east, bordering on Xiongxian on the west, adjacent to Wenan on the south and bordering on Guan, Yongqing and Anci district of Langfang City on the north, it covers an area of 80027.25 square kilometers, among which 57348.41 hectares of farmland, accounting for $71.7 \%$ of the total area.

\subsection{An Attempt to Calculate the Social Stability Price}

\subsubsection{Direct Method}

Here the production safety price of the first part is calculated. The concrete process is as follows: taking the practical situation of Hebei province into consideration, evaluate the function of the production capacity of farmland of Bazhou city in Hebei province and get the weight. Then consider the food safety in Hebei province and arable land reduction of Bazhou city within a certain planning period, get the food safety value that farmland in Bazhou city should have in the planning period, quantify it and obtain the production safety price of farmland in Bazhou city.

According to the statistics of 2003, the grain out of Hebei province was 23.878 million ton and that of Bazhou city was 177.198 thousand ton.

Calculate the production safety weight of Bazhou city:

$$
\begin{aligned}
\text { PS } & =\text { grain output of the small area/grain output of the large area } \\
& =\text { grain output of Bazhou city/grain output of Hebei province } \\
& =177198 / 2387.8 \\
& =0.0074
\end{aligned}
$$

Based on the population base and the natural growth rate of Hebei Province in 2003, it is predicated that the population of Hebei will reach 70.2318 million in 2010 . If $350 \mathrm{~kg}$ of grain per capita is determined to be the survival safety standards, $24581130647 \mathrm{~kg}$ will be needed. If $420 \mathrm{~kg}$ of grain per capita is the nutrition safety standards, $29497356776 \mathrm{~kg}$ will be needed. Based on the grain output of Hebei province, the food gap is $703130646.8 \mathrm{~kg}$ and $5619356776 \mathrm{~kg}$ respectively. Taking PS, the production safety weight of farmland of Bazhou city, into account, the selling price of wheat is converted into the production safety price of farmland and the total amount of production safety function value of farmland in Bazhou city is obtained. 
SZ1=quantity demanded for survival safety in Hebei provincexproduction safety weight of Bazhou city $\times$ selling price of wheat

$$
\begin{aligned}
& =703130646.8 \times 0.0074 \times 0.7 \\
& =3642216.75 \text { (yuan) }
\end{aligned}
$$

SZ2 = quantity demanded for nutrition safety in Hebei provincexproduction safety weight of Bazhou city $\times$ selling price of wheat

$$
\begin{aligned}
& =5619356776 \times 0.0074 \times 0.7 \\
& =29108268.1 \quad \text { (yuan) }
\end{aligned}
$$

The area under cultivation in Bazhou city at the beginning of 2002 was 48830 hectares and the area at the end of 2003 was 46148 hectares, reducing by 1341 hectares annually. Based on this reduction amplitude, by the year of 2010, the area under cultivation in Bazhou city will have reduced to 36761 hectares. Let's assume that the production level remains the same as the present level and the influence by scientific progress and social economy are not taken into consideration. That is to say, the various influencing factors except the amount and the safety need amount all remain the same. So the production safety price in a unit area changes into the function of the amount and the safety need amount. Then the amount of the production safety value of farmland in a unit area is obtained by calculation with the equation above. Namely,

Survival safety price in a unit area:

$\mathrm{S}=f$ (total amount of safety need, area under cultivation at the end of the period)

$=\mathrm{SZ} 1 /$ area under cultivation at the end of the period $=3642216.75 / 36761$

$=99.08$ (yuan/hectare)

nutrition safety price in a unit area:

$\mathrm{S}=f$ (total amount of safety need, area under cultivation at the end of the period)

$=\mathrm{SZ} 2 /$ area under cultivation at the end of the period $=29108268.1 / 36761$

$=791.82$ (yuan/hectare)

\subsubsection{Indirect Method}

The equation above is adopted.

$$
\begin{aligned}
& \mathrm{V} 1=\mathrm{T}+\mathrm{T} /(1+\mathrm{r})+\mathrm{T} /(1+\mathrm{r}) 2+\mathrm{T} /(1+\mathrm{r}) 3+\mathrm{T} /(1+\mathrm{r}) 4 \\
& \mathrm{~V} 2=\mathrm{P} /(1+\mathrm{r})+\mathrm{P} /(1+\mathrm{r}) 2+\mathrm{P} /(1+\mathrm{r}) 3+\mathrm{P} /(1+\mathrm{r}) 4 \\
& \text { social stability price }: \quad \mathrm{V}=\mathrm{V} 1+\mathrm{V} 2
\end{aligned}
$$

According to a survey, the average input level each year into agricultural production in Bazhou city is 5250 - 9900 yuan per hectare and the output level is 15000 yuan per hectare. The annual input into land reclamation is 9900 yuan per hectare and the interest rate is $3 \%$. Therefore, the present value of input into land reclamation is

$$
\begin{aligned}
\mathrm{V} 1 & =9900+9900 /(1+3 \%)+9900 /(1+3 \%) 2+9900 /(1+3 \%) 3+9900 /(1+3 \%) 4 \\
& =46699.2 \text { (yuan/hectare) }
\end{aligned}
$$

The present value of loss in revenue for 4 years is

$$
\begin{aligned}
\mathrm{V} 2 & =15000 /(1+3 \%)+15000 /(1+3 \%) 2+15000 /(1+3 \%) 3+15000 /(1+3 \%) 4 \\
& =55756.5 \text { (yuan/hectare) }
\end{aligned}
$$

Therefore, $\mathrm{V}=\mathrm{V} 1+\mathrm{V} 2=102455.7$ (yuan/hectare) ) 


\section{Discussion}

The result of the direct calculation has already deducted the amount of grain based on the production capacity of farmland and the production safety price of it is calculated, with the reduction of arable land taken into consideration. As the safety function of grain production of farmland is calculated, arable land is considered rather than other kinds of farmland. When the social stability price of farmland is calculated, the price of only one kind of crop - wheat, is calculated and the increase in grain yield due to the scientific progress and the increase in the input into social economy is not considered. In practice, the price of many kinds of crops should be used in the calculation and the influence of social progress and increase in input into social economy on the increase in grain yield should also be considered when the production safety price of farmland is determined. In addition, the calculation only covers the production safety price and does not involve the safety function price of the other three kinds due to differnt calculation method and data source.

Compare the result of the direct calculation and that of the indirect calculation, we can see that there is great difference in fees used for cultivating land and the safety price, as the direct calculation does not take the other three kinds of price into consideration.

\section{References}

1. Liu, X.: On Choice of Strategic Objectives and Models of Food Security in China. Journal of Shanxi Finance and Economics University 26(3) (2004)

2. Liu, L.: Land Resource Science, pp. 6-7. China Agricultural University Press, Beijing (2001)

3. Liu, H.: On Composition and Quantification of Farmland Price in China. Land Science of China (2000) 